\title{
Control Structure Selection Based on Economics: Generalization of the Back-Off Methodology
}

DOI:

10.1002/aic. 15284

Document Version

Accepted author manuscript

Link to publication record in Manchester Research Explorer

\section{Citation for published version (APA):}

Kookos, I., \& Perkins, J. (2016). Control Structure Selection Based on Economics: Generalization of the Back-Off Methodology. AlChE Journal, 62(9), 3056-3064. https://doi.org/10.1002/aic.15284

\section{Published in:}

AlChE Journal

\section{Citing this paper}

Please note that where the full-text provided on Manchester Research Explorer is the Author Accepted Manuscript or Proof version this may differ from the final Published version. If citing, it is advised that you check and use the publisher's definitive version.

\section{General rights}

Copyright and moral rights for the publications made accessible in the Research Explorer are retained by the authors and/or other copyright owners and it is a condition of accessing publications that users recognise and abide by the legal requirements associated with these rights.

\section{Takedown policy}

If you believe that this document breaches copyright please refer to the University of Manchester's Takedown Procedures [http://man.ac.uk/04Y6Bo] or contact uml.scholarlycommunications@manchester.ac.uk providing relevant details, so we can investigate your claim.

\section{OPEN ACCESS}




\title{
Control Structure Selection Based on Economics: Generalization of the Back-Off Methodology
}

\author{
Ioannis K. Kookos \\ Dept. of Chemical Engineering, University of Patras, Rio, Patras 26504, Greece \\ John D. Perkins \\ School of Chemical Engineering and Analytical Science, University of Manchester, Manchester M13 9PL, UK
}

DOI 10.1002/aic.15284

Published online in Wiley Online Library (wileyonlinelibrary.com)

\begin{abstract}
The back-off methodology has been extensively developed and refined in the last 20 years and offers a systematic tool for solving the simultaneous design and control problem. Previous work has been based on linear process and control models that ensure quick determination of the optimal solution at the expense of potential loss in the accuracy due to nonlinear process characteristics. In this work a new formulation is proposed where use is made of a nonlinear process model that ensures improved accuracy and also offers an improved opportunity for the simultaneous consideration of process design and process control. Two case studies are studied in detail and demonstrate the advantages of the new formulation. (C) 2016 American Institute of Chemical Engineers AIChE J, 00: 000-000, 2016
\end{abstract}

Keywords: control structure selection, mathematical programming, evaporator process model, ternary reactive distillation

\section{Introduction}

The design of chemical processes is carried out with the aim to generate an optima1 plant which satisfies all operating constraints and demands in a constantly changing environment. Continuous processes have traditionally been designed to achieve optimality around a nominal steady state operating point. This is based on the assumption that an appropriate and efficient control system will be added at a later stage that will ensure operation close to this nominal point. This sequential approach to plant design and control can result in suboptimal plants which may be unable to meet operational requirements. This problem has led industry and academia to develop methodologies to include plant operability/controllability considerations at the early design stages.

One approach to tackle the combined operability and economics objectives is to assess the effect of disturbances on process economics. As different process designs and control system designs have different dynamic characteristics the aim is to design them simultaneously so as to achieve robust economic performance, i.e., reduce sensitivity of economic performance to disturbances. As designers have no control on disturbances that are generated exogenously to the process under study the aim is to direct the process variability to variables that do not have a strong influence on process economics.

A systematic method, that is known as the back-off methodology for simultaneous design and control, based on these ideas has been proposed by Narraway and Perkins ${ }^{1,2}$ and was latter refined by Perkins and his co-workers. ${ }^{3-6}$ More recently

\footnotetext{
Correspondence concerning this article should be addressed to I. K. Kookos at i.kookos@chemeng.upatras.gr.

(C) 2016 American Institute of Chemical Engineers
}

Psaltis et al. ${ }^{7,8}$ proposed some implementation improvements that made the application of the methodology possible to plantwide control problems. A large number of alternative methodologies for the solution of the problem of selecting regulatory structures have also been developed. ${ }^{9-16}$

The back-off methodology is based on the assumption that the optimal steady state operating point is defined by the intersection of active constraints. This is a well established fact that is critical to the design of successful control systems. If, for instance, the set of active constraints does not change as disturbances act on the plant then direct control of the active constraints results in a near optimal system under static and dynamic conditions. However, perfect control of the active constraints cannot be achieved and, to make things even worse, the set of active constraints can vary under dynamic conditions (see Refs. 17 and 18 for a comprehensive discussion) and/or active constraints may not be measurable. In addition, there is usually available a large number of potential manipulated variables and secondary measurements, consideration of which results in an exploding number of possible combinations that need to be considered before an optimal structure is established. In the back-off methodology mathematical programming techniques are utilized for the systematic representation of alternatives (superstructure representation) and the solution of the problem (quick ranking of alternatives and identification of optimal solution).

In the mathematical formulation of the classical back-off methodology use is made of linear control theory combined with a linear model of process economics. The reason for using linear models is to exploit the benefits of both linear control theory and linear programming so as to quickly evaluate alternative control structures and locate the optimal 
structure and possibly optimal design. The obvious shortcoming is related to the loss of accuracy that accompanies the use of linear models that can be severe for plants with highly nonlinear dynamics. In this work it is proposed to use a nonlinear model for evaluating process economics with an approximate linear model for evaluating controller performance. A short review of the back-off methodology is first presented and then the necessary modifications for the incorporation of a nonlinear model of process economics are described. To evaluate the usefulness of the new systematic methodology two case studies are considered and studied in detail: an evaporator and a ternary reactive distillation with a chemically inert component in the feed. The results obtained for both case studies demonstrate the potential of the proposed methodology for solving challenging control structure selection problems in an efficient and effective way.

\section{Mathematical Framework and Formulation}

Operation of chemical process systems may be modeled by a set of nonlinear differential and algebraic equations and inequality constraints that involve an $n_{\mathrm{x}}$ vector of state variables $\mathbf{x}(t)$, an $n_{\mathrm{z}}$ vector of algebraic variables $\mathbf{z}(t)$, an $n_{\mathrm{u}}$ vector of control variables $\mathbf{u}(t)$, a vector of design variables that consist of continuous $(\mathbf{d})$ as well as integer $(\boldsymbol{\Delta})$ variables and an $n_{\mathrm{p}}$ vector of disturbances $\mathbf{p}(t)$ (variables that are determined exogenously)

$$
\begin{gathered}
\mathbf{h}(\dot{\mathbf{x}}(t), \mathbf{x}(t), \mathbf{z}(t), \mathbf{u}(t), \mathbf{p}(t) ; \mathbf{d}, \Delta)=0 \\
\mathbf{g}(\mathbf{x}(t), \mathbf{z}(t), \mathbf{u}(t), \mathbf{p}(t) ; \mathbf{d}, \Delta) \leq 0
\end{gathered}
$$

To achieve optimal design and operation of a process, it is common practice to perform steady state optimization using appropriate economic performance indices (denoted by $J()$ ). To this end, the disturbances that affect the system under study are assumed to take their nominal values (denoted by subscript $N) \mathbf{p}=\mathbf{p}_{\mathrm{N}}$ and the following problem is solved

$$
\begin{gathered}
\min _{\mathbf{x}_{s}, \mathbf{z}_{s}, \mathbf{u}_{s} ; \mathbf{d}, \Delta} J\left(\mathbf{x}_{s}, \mathbf{z}_{s}, \mathbf{u}_{s}, \mathbf{p}_{N} ; \mathbf{d}, \Delta\right) \\
\text { s.t. } \\
\mathbf{h}\left(\mathbf{x}_{s}, \mathbf{z}_{s}, \mathbf{u}_{s}, \mathbf{p}_{N} ; \mathbf{d}, \Delta\right)=0 \\
\mathbf{g}\left(\mathbf{x}_{s}, \mathbf{z}_{s}, \mathbf{u}_{s}, \mathbf{p}_{N} ; \mathbf{d}, \Delta\right) \leq 0
\end{gathered}
$$

The solution of problem (2) normally lies at the intersection of some of the inequality constraints that define the region of feasible operation. ${ }^{17,18}$ Following the determination of the optimal design $(\mathbf{d}, \boldsymbol{\Delta})$, and operating point $\left(\mathbf{x}_{\mathrm{s}}, \mathbf{z}_{\mathrm{s}}, \mathbf{u}_{\mathrm{s}}\right)$ for the nominal values of the disturbances, attention is shifted to ensure feasibility and optimality for the complete set of uncertainties. One approach is to revise formulation (2) so as to incorporate the elements of uncertainty and solve the feasibility and optimality problem simultaneously. ${ }^{19,20}$

The back-off methodology is a sequential methodology in which the effects of disturbances are studied around the nominal optimal point. The aim is to develop systematically efficient regulatory control structures so as to alleviate the effect of disturbances. The underlying idea is that the plant cannot operate at the optimal operating point as disturbances will cause infeasible operation irrespective of the efficiency of the controller used. As a result normal operation will take place around a point which is determined by using an appropriate back-off, denoted by the vector $\boldsymbol{\mu}$, from the vector of inequality constraints.

$$
\begin{gathered}
\min _{\mathbf{x}_{s}, \mathbf{z}_{s}, \mathbf{u}_{s} ; \mathbf{d}, \mathbf{X}} J\left(\mathbf{x}_{s}, \mathbf{z}_{s}, \mathbf{u}_{s}, \mathbf{p}_{N} ; \mathbf{d}, \Delta\right) \\
\text { s.t. } \\
\mathbf{h}\left(\mathbf{x}_{s}, \mathbf{z}_{s}, \mathbf{u}_{s}, \mathbf{p}_{N} ; \mathbf{d}, \Delta\right)=0 \\
\mathbf{g}\left(\mathbf{x}_{s}, \mathbf{z}_{s}, \mathbf{u}_{s}, \mathbf{p}_{N} ; \mathbf{d}, \Delta\right) \leq-\boldsymbol{\mu}
\end{gathered}
$$

The back-off vector is a function of the characteristics of the disturbances, the structure (interconnection) and parameters of the controller (tunable parameters) and the design of the plant (as it affects its dynamic performance).

To determine the back-off vector and simultaneously solve the regulatory control structure selection problem we start by developing the linearized model of the process around the nominal optimal point

$$
\begin{aligned}
\delta \dot{\mathbf{x}}(t) & =\mathbf{A} \delta \mathbf{x}(t)+\mathbf{B} \delta \mathbf{u}(t)+\mathbf{E} \delta \mathbf{p} \\
\delta \mathbf{y}(t) & =\mathbf{C} \delta \mathbf{x}(t)+\mathbf{D} \delta \mathbf{u}(t)+\mathbf{F} \delta \mathbf{p} \\
\delta \mathbf{g}(t) & =\mathbf{H} \delta \mathbf{x}(t)+\mathbf{P} \delta \mathbf{u}(t)+\mathbf{S} \delta \mathbf{p}
\end{aligned}
$$

where $\delta$ denotes deviation from the value at the optimal steady state operating point $\left(\delta \mathbf{x}(t)=\mathbf{x}(t)-\mathbf{x}_{\mathrm{s}}, \ldots\right)$ and the definition of the matrices appearing in Eq. 4 can be found in Heath et al. ${ }^{4}$ We then obtain the Laplace transform of all time dependent vectors (denoted by the corresponding capital letter, i.e., $X=L\{\delta \mathbf{x}(t)\}, \ldots)$ and decompose the transformed variables into real (denoted by superscript $\mathrm{R}$ ) and imaginary (denoted by superscript I) parts (i.e., $X=X^{\mathrm{R}}+i X^{\mathrm{I}}, \ldots$ ). The transformed Eq. 4, in which time is the independent variable, can be written in the following form (where frequency is the independent variable)

$$
\begin{gathered}
0=\mathbf{A} X^{R}+\mathbf{B} U^{R}+\mathbf{E} P^{R}+\omega X^{I} \\
0=\mathbf{A} X^{I}+\mathbf{B} U^{I}+\mathbf{E} P^{I}-\omega X^{R} \\
Y^{R}=\mathbf{C} X^{R}+\mathbf{D} U^{R}+\mathbf{F} P^{R} \\
Y^{I}=\mathbf{C} X^{I}+\mathbf{D} U^{I}+\mathbf{F} P^{I} \\
G^{R}=\mathbf{H} X^{R}+\mathbf{P} U^{R}+\mathbf{S} P^{R} \\
G^{I}=\mathbf{H} X^{I}+\mathbf{P} U^{I}+\mathbf{S} P^{I}
\end{gathered}
$$

If we set $P^{\mathrm{R}}=1$ and $P^{\mathrm{I}}=0$ then we can obtain the frequency response of the system (i.e., the asymptotic response to sinusoidal variation of the disturbances with frequency $\omega$ ). By varying $\omega$ or using several values of $\omega$ we can construct the complete frequency response. However, the system of linear equations (5) is underdetermined as $2 n_{\mathrm{u}}$ equations are missing. These are the equations that are needed to describe the controller in the frequency domain.

To resolve this issue and at the same time avoid the introduction of the controller design problem Narraway and Perkins $^{1,2}$ propose using a perfect control approach. Integer variables $\Psi_{j}$ are introduced to denote the selection $\left(\Psi_{j}=0\right)$ or not $\left(\Psi_{j}=1\right)$ of potential controlled variable $y_{j}$ in the regulatory control structure and perfect control is implemented through the following linear inequalities

$$
\left.\begin{array}{l}
-y_{j}^{U} \Psi_{j} \leq Y_{j}^{R} \leq y_{j}^{U} \Psi_{j} \\
-y_{j}^{U} \Psi_{j} \leq Y_{j}^{I} \leq y_{j}^{U} \Psi_{j}
\end{array}\right\} j=1,2, \cdots, n_{y}
$$

In a similar way the integer variables $\Theta_{j}$ are introduced to select $\left(\Theta_{j}=1\right)$ or not $\left(\Theta_{j}=0\right)$ a potential manipulated variable $u_{j}$ in the control structure 


$$
\left.\begin{array}{l}
-u_{j}^{U} \Theta_{j} \leq U_{j}^{R} \leq u_{j}^{U} \Theta_{j} \\
-u_{j}^{U} \Theta_{j} \leq U_{j}^{I} \leq u_{j}^{U} \Theta_{j}
\end{array}\right\} j=1,2, \cdots, n_{u}
$$

Consideration is also restricted to square control structures

$$
\sum_{j=1}^{n_{y}} \Psi_{j}+\sum_{j=1}^{n_{u}} \Theta_{j}=n_{y}
$$

Psaltis et al. ${ }^{7}$ have shown that the back-off vector can be determined accurately through the following set of linear inequalities that avoid the need for the iterative application of the algorithm used by Narraway and Perkins ${ }^{2}$ and Heath et al. ${ }^{4}$

$$
\boldsymbol{\Pi}^{R} G^{R}+\boldsymbol{\Pi}^{I} G^{I} \leq \boldsymbol{\mu}
$$

For the particular structure of the constant matrices $\boldsymbol{\Pi}^{R}$ and $\boldsymbol{\Pi}^{I}$ the reader is referred to Psaltis et al. ${ }^{7}$

Based on the above developments previous efforts to solve the control structure selection were based on Eqs. 5-9 (with Eq. 5 and 9 expressed for each frequency and disturbance) coupled with the linearized system at steady state

$$
\begin{gathered}
\min _{\delta \mathbf{x}, \delta \mathbf{u}, \Theta, \Psi, \boldsymbol{\mu}} E P_{l p}=J_{x}^{T} \delta \mathbf{x}+J_{u}^{T} \delta \mathbf{u} \\
\text { s.t. } \\
\mathbf{A} \delta \mathbf{x}+\mathbf{B} \delta \mathbf{u}=0 \\
\mathbf{C} \delta \mathbf{x}+\mathbf{D} \delta \mathbf{u}=\delta \mathbf{y} \\
\mathbf{g}_{N}+\mathbf{H} \delta \mathbf{x}(t)+\mathbf{P} \delta \mathbf{u} \leq-\boldsymbol{\mu} \\
-\delta \mathbf{x}^{U} \leq \delta \mathbf{x} \leq \delta \mathbf{x}^{U} \\
-\delta \mathbf{u}^{U} \leq \delta \mathbf{u} \leq \delta \mathbf{u}^{U} \\
\Theta_{j}, \Psi_{j} \in\{0,1\}
\end{gathered}
$$

Eqs. 5-9

where $J_{x}$ is the (gradient) vector of partial derivatives of the objective function $(J)$ with respect to the state vector, $J_{u}$ is the vector of partial derivatives of the objective function with respect to the control vector and $E P_{l p}$ is the economic penalty resulting from the occurrence of the disturbances calculated using a linearized model for the process economics.

The computational power that is widely available today together with improvements in optimization algorithms and software allows us to follow a more ambitious path. More specifically, instead of relying on the linearized economic model, as expressed by formulation (10), we can calculate a more accurate estimation of economics using the nonlinear model given by Eq. 3 with the necessary modifications

$$
\begin{gathered}
\min _{\mathbf{x}_{s}, \mathbf{z}_{s}, \mathbf{u}_{s} ; \mathbf{d}, \Delta, \Theta, \Psi, \boldsymbol{\mu}} E P_{n l p}=\left.J\right|_{\boldsymbol{\mu} \neq 0}\left(\mathbf{x}_{s}, \mathbf{z}_{s}, \mathbf{u}_{s}, \mathbf{p}_{N} ; \mathbf{d}, \Delta\right)-\left.J\right|_{\boldsymbol{\mu}=0} \\
\text { s.t. } \\
\mathbf{h}\left(\mathbf{x}_{s}, \mathbf{z}_{s}, \mathbf{u}_{s}, \mathbf{p}_{N} ; \mathbf{d}, \Delta\right)=0 \\
\mathbf{g}\left(\mathbf{x}_{s}, \mathbf{z}_{s}, \mathbf{u}_{s}, \mathbf{p}_{N} ; \mathbf{d}, \Delta\right) \leq-\boldsymbol{\mu} \\
\Theta_{j}, \Psi_{j} \in\{0,1\}
\end{gathered}
$$

Eqs. 5-9

where $\left.J\right|_{\mu=0}$ is the solution of problem (2) (to which problem (11) simplifies when $\mu=0$ ).

Formulation (10) is a mixed integer linear programming problem (MILP) that can be used to rank alternative control structures using $E P_{l p}$. A wide spectrum of solution algorithms is available for solving efficiently MILP problems to global optimallity $^{21,22}$ and Psaltis et al., ${ }^{7,8}$ have solved large scale problems including the benchmark plantwide control problem of the vinyl acetate monomer plant.

Formulation (11), conversely, is a mixed integer nonlinear problem (MINLP) for which efficient solution algorithms have become available in the last 10-15 years. A good initial point can always be found easily by using the solution of problem (2) and, as the disturbances considered are normally very close to their nominal values, convergence is expected to be rapid. Global optimality cannot be guaranteed in this case due to nonconvexities in the nonlinear model of the plant. An important advantage of the nonlinear formulation (11) is that it constitutes a case of simultaneous design and control formulation where continuous design decision variables can be revised together with the selection of the control structure so as to improve dynamic economics. Binary design variables that are related to the structural optimization of the plant $(\Delta)$ can be included in formulation (11) but this is correct as far as the structural design decisions do not interfere with the structural decisions related to the control structure. This, for instance, excludes the cases where by varying the integer variables $\Delta$ alters the structure of the potential controlled or manipulated variables vectors.

A final note that can be made is related to the use of a linear approximation of the objective function with respect to the state and control variables. This is usually adequate as the objective function is in many cases a linear function of the manipulated or state variables. In the cases where the linear approximation is not adequate a quadratic approximation can be used to improve the accuracy of the approximation

$$
\min _{\delta \mathbf{x}, \delta \mathbf{u}, \Theta, \Psi, \mu} E P_{q p}=J_{x}^{T} \delta \mathbf{x}+J_{u}^{T} \delta \mathbf{u}+\frac{1}{2}\left[\begin{array}{ll}
\delta \mathbf{x}^{T} & \delta \mathbf{u}^{T}
\end{array}\right] Q\left[\begin{array}{c}
\delta \mathbf{x} \\
\delta \mathbf{u}
\end{array}\right]
$$

$$
\text { s.t. }
$$

$$
\begin{gathered}
\mathbf{A} \delta \mathbf{x}+\mathbf{B} \delta \mathbf{u}=0 \\
\mathbf{C} \delta \mathbf{x}+\mathbf{D} \delta \mathbf{u}=\delta \mathbf{y} \\
\mathbf{g}_{N}+\mathbf{H} \delta \mathbf{x}(t)+\mathbf{P} \delta \mathbf{u} \leq-\boldsymbol{\mu} \\
-\delta \mathbf{x}^{U} \leq \delta \mathbf{x} \leq \delta \mathbf{x}^{U} \\
-\delta \mathbf{u}^{U} \leq \delta \mathbf{u} \leq \delta \mathbf{u}^{U} \\
\Theta_{j}, \Psi_{j} \in\{0,1\}
\end{gathered}
$$

resulting in a mixed integer quadratic programming problem.

In the following section we present two case studies with the aim to demonstrate the efficiency of the proposed approach for the selection of regulatory control structures based on linear or nonlinear dynamic economics. The first case study is a single effect evaporator whose model has been developed and validated experimentally by Newell and Lee. ${ }^{23}$ The model has been modified and augmented by an appropriate economic model and a set of inequality constraints and used extensively in control structure selection case studies. ${ }^{4,5}$ The second case study involves a ternary reactive distillation column with a chemically inert component in the feed. ${ }^{24}$ Previous studies have concluded that no efficient two-point control scheme can be devised based solely on temperature (and not composition) measurements across the column. It will be shown that a working structure can be developed systematically based on the mathematical formulations reviewed or proposed in this work. This will clearly demonstrate the advantages of the proposed 
methodology for the unambiguous selection of efficient regulatory control structures. All numerical optimizations were performed in GAMS using the CPLEX LP/MILP solver and the SBB NLP/MINLP solver. ${ }^{25}$ The selection of the SBB solver, over other MINLP solvers available in GAMS, was based on the fact that it was proven more robust in solving the problem under study.

\section{Single Effect Evaporator Case Study}

The evaporation process examined in this case study is shown in Figure 1. ${ }^{4,5,23}$ This is a process that removes a volatile liquid from a non-volatile solute, thus concentrating the solution. It consists mainly of a heat exchange vessel with a recirculating pump. The vapour is condensed by the use of a process heat exchanger. The major variables of interest are summarized in Table 1 while the dynamic model of the evaporator is given by

\section{Equality constraints}

$$
\begin{gathered}
M \frac{d C_{2}}{d t}-F_{1} C_{1}+F_{2} C_{2}=0 \\
C \frac{d P_{2}}{d t}-F_{4}+F_{5}=0 \\
F_{1}-F_{4}-F_{2}=0 \\
F_{1} C_{p} T_{1}-F_{4}\left(\lambda+C_{p} T_{4}\right)-F_{2} C_{p} T_{2}+Q_{100}=0 \\
0.5616 P_{2}+0.3126 C_{2}+48.43-T_{2}=0 \\
0.5070 P_{2}+55-T_{4}=0 \\
0.1538 P_{100}+90-T_{100}=0 \\
Q_{100}-U A_{1}\left(T_{100}-T_{2}\right)=0 \\
Q_{100}-F_{100} \lambda_{S}=0 \\
Q_{200}-F_{200} C_{P}\left(T_{201}-T_{200}\right)=0 \\
Q_{200}-U A_{2}\left(T_{4}-\left(T_{201}+T_{200}\right) / 2\right)=0 \\
F_{5} \lambda-Q_{200}=0
\end{gathered}
$$

\section{Inequality constraints}

$$
\begin{gathered}
g_{1}=25-C_{2} \leq 0 \\
g_{2}=40-P_{2} \leq 0 \\
g_{3}=P_{2}-80 \leq 0 \\
g_{4}=P_{100}-400 \leq 0 \\
g_{5}=F_{200}-400 \leq 0
\end{gathered}
$$

\section{Objective function (operating cost in \$/y)}

$$
J=0.6\left(F_{100}+10^{-3} F_{200}\right) 8000
$$

where $C_{P}=0.07 \mathrm{~kW} / \mathrm{kg}, \lambda=38.5 \mathrm{~kW} / \mathrm{kg}, \lambda_{\mathrm{S}}=36.6 \mathrm{~kW} / \mathrm{kg}$, $U A_{1}=9.6 \mathrm{~kW} /{ }^{\circ} \mathrm{C}$, and $U A_{2}=6.84 \mathrm{~kW} /{ }^{\circ} \mathrm{C}$. We further define the following vectors

$$
\mathbf{x}=\left[\begin{array}{c}
C_{2} \\
P_{2}
\end{array}\right], \quad \mathbf{y}=\left[\begin{array}{c}
C_{2} \\
P_{2} \\
T_{201}
\end{array}\right], \quad \mathbf{u}=\left[\begin{array}{c}
P_{100} \\
F_{200}
\end{array}\right], \quad \mathbf{p}=\left[\begin{array}{c}
F_{1} \\
C_{1}
\end{array}\right]
$$

To find the optimum point of steady state operation the following nominal input conditions are selected: $F_{1}=10 \mathrm{~kg} / \mathrm{min}$,

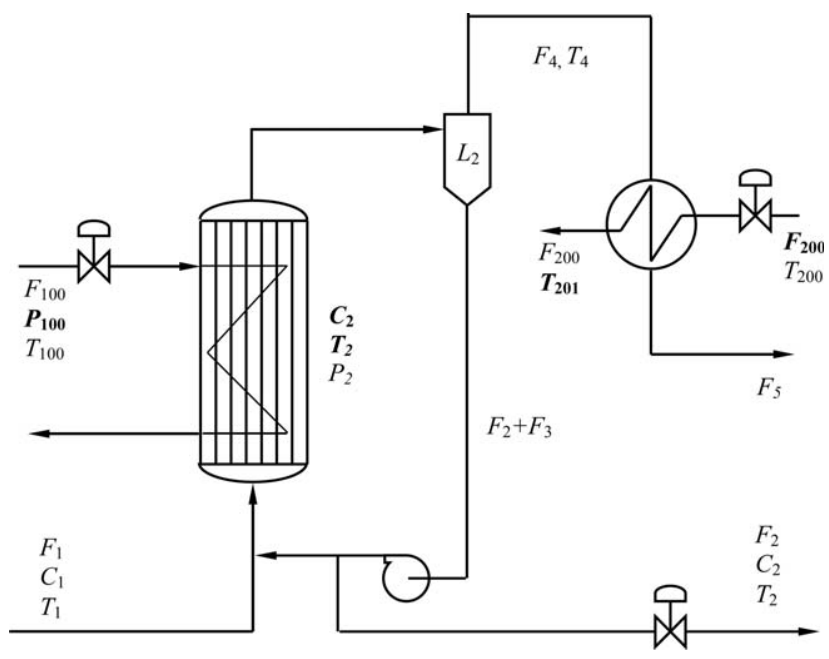

Figure 1. Single effect evaporator system.

$C_{1}=5 \%$. Table 1 summarizes the results of the optimization for this nominal case while the corresponding objective function is $45,193.1 \$ / y$. The product purity constraint is the only constraint that is active at the optimal point.

The application of the back-off methodology using both the nonlinear (Eq. 11) and linear (Eq. 10) models for dynamic economics is summarized in Table 2 for the case of simultaneous $10 \%$ variation in both disturbances. It should be noted that as the model is linear and the magnitude of the back-off vector is calculated the actual sign of the disturbance makes no difference. We observe that five out of nine potential closed loop structures exhibit better economics than the open loop case. There is an infeasible structure in which excessive variation of the input is necessary to achieve perfect control. There are also three closed loop structures that are worse than the open loop structure. The relative ranking of the potential control structures remains the same irrespective of the linear or nonlinear formulation. In spite of the small differences in the calculated economic penalty the proposed methodology is successful in ranking all potential control structures. It also helps to gain insight into the characteristics of a successful control structure for the system under study. Controlling the active constraint, which is measurable, is vital in achieving acceptable closed loop performance characterized by small economic penalties.

Table 1. Major Variables of the Evaporation Process Model and Their Values at Optimal Nominal Operating Point

\begin{tabular}{llrl}
\hline Notation & \multicolumn{1}{c}{ Variable } & Value & Units \\
\hline $\mathrm{F}_{1}$ & Fresh feed mass flowrate & 10.000 & $\mathrm{~kg} / \mathrm{min}$ \\
$\mathrm{F}_{2}$ & Product mass flowrate & 2.000 & $\mathrm{~kg} / \mathrm{min}$ \\
$\mathrm{F}_{4}$ & Vapor mass flowrate & 8.000 & $\mathrm{~kg} / \mathrm{min}$ \\
$\mathrm{F}_{5}$ & Condensate mass flowrate & 8.000 & $\mathrm{~kg} / \mathrm{min}$ \\
$\mathrm{F}_{100}$ & Steam mass flowrate & 9.208 & $\mathrm{~kg} / \mathrm{min}$ \\
$\mathrm{F}_{200}$ & Cooling water mass flowrate & 207.323 & $\mathrm{~kg} / \mathrm{min}$ \\
$\mathrm{T}_{1}$ & Feed temperature & 40.000 & ${ }^{\circ} \mathrm{C}$ \\
$\mathrm{T}_{2}$ & Product temperature & 84.647 & ${ }^{\circ} \mathrm{C}$ \\
$\mathrm{T}_{4}$ & Vapor temperature & 80.641 & ${ }^{\circ} \mathrm{C}$ \\
$\mathrm{T}_{100}$ & Steam temperature & 119.752 & ${ }^{\circ} \mathrm{C}$ \\
$\mathrm{T}_{200}$ & Cooling water inlet temperature & 25.000 & ${ }^{\circ} \mathrm{C}$ \\
$\mathrm{T}_{201}$ & Cooling water outlet temperature & 46.223 & ${ }^{\circ} \mathrm{C}$ \\
$\mathrm{C}_{1}$ & Feed composition & 5.000 & ${ }^{\circ} \%$ \\
$\mathrm{C}_{2}$ & Product composition & 25.000 & $\%$ \\
$\mathrm{P}_{2}$ & Operating pressure & 50.573 & $\mathrm{kPa}$ \\
$\mathrm{P}_{100}$ & Steam pressure & 193.447 & $\mathrm{kPa}$ \\
\hline
\end{tabular}


Table 2. Results of the Evaporator Case Study-Nonlinear and Linear Dynamic Economics for 10\% Simultaneous Variation in Disturbances

\begin{tabular}{|c|c|c|c|c|c|c|c|}
\hline \multirow[b]{2}{*}{ Structure } & \multicolumn{3}{|c|}{ Controlled variables } & \multicolumn{2}{|c|}{$\begin{array}{c}\text { Manipulated } \\
\text { variables }\end{array}$} & \multicolumn{2}{|c|}{ Economic penalty } \\
\hline & $\mathrm{C}_{2}$ & $\mathrm{P}_{2}$ & $\mathrm{~T}_{201}$ & $\mathrm{P}_{100}$ & $\mathrm{~F}_{200}$ & $E P_{n l p}(\$ / \mathrm{y}) /(\%$ of $J)$ & $E P_{l p}(\$ / \mathrm{y}) /(\%$ of $J)$ \\
\hline 1 & $\sqrt{ }$ & $\sqrt{ }$ & & $\sqrt{ }$ & $\sqrt{ }$ & $0.00 /(0.0 \%)$ & $0.00 /(0.0 \%)$ \\
\hline 2 & $\sqrt{ }$ & & v & $\sqrt{ }$ & $\checkmark$ & $0.62 /(0.0 \%)$ & $0.02 /(0.0 \%)$ \\
\hline 3 & j & & & $\sqrt{ }$ & & $19.54 /(0.0 \%)$ & $0.14 /(0.0 \%)$ \\
\hline 4 & & $\downarrow$ & & & $\sqrt{ }$ & $2,444.45 /(5.4 \%)$ & $3,109.11 /(6.8 \%)$ \\
\hline 5 & & & ل & & $\sqrt{ }$ & $3,128.25 /(6.9 \%)$ & $4,306.46 /(9.5 \%)$ \\
\hline 6 OPEN LOOP & & & & & & $3,200.78 /(7.1 \%)$ & $4,445.15 /(9.8 \%)$ \\
\hline 7 & & ل & & ل & & $3,819.78 /(8.5 \%)$ & $5,736.26 /(12.7 \%)$ \\
\hline 8 & & & 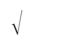 & $\sqrt{ }$ & & $3,819.78 /(8.5 \%)$ & $5,736.26 /(12.7 \%)$ \\
\hline 9 & & ل & ل & $\sqrt{ }$ & $\sqrt{ }$ & $3,819.78 /(8.5 \%)$ & $5,736.26 /(12.7 \%)$ \\
\hline 10 & $\sqrt{ }$ & & & & $\sqrt{ }$ & Infeasible & Infeasible \\
\hline
\end{tabular}

\section{Ternary Reactive Distillation Column with a Chemically Inert Component}

In this case study a ternary reactive distillation is considered in which the following reversible and exothermic reaction is taking place in the liquid phase on the reactive trays ${ }^{24}$

$$
\mathrm{A}+\mathrm{B} \Longleftrightarrow \mathrm{C}
$$

The reaction rate $r$ (in $\mathrm{kmol} / \mathrm{h}$ ) is expressed in terms of the mole fractions in the liquid phase

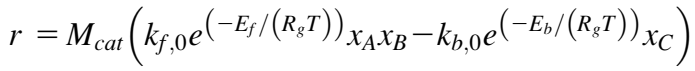

where $M_{c a t}$ is the mass of catalyst used, $k_{f, 0}$ and $k_{b, 0}$ are the pre-exponential factors and $E_{f}$ and $E_{b}$ the activation energies of the forward and backward reactions, respectively. Product $\mathrm{C}$ is the heaviest component while reactant $\mathrm{A}$ is the lightest component. The relative volatilities of the reactants lie between the volatilities of the product and inert

$$
\alpha_{\mathrm{I}}=\alpha_{\mathrm{A}}>\alpha_{\mathrm{B}}>\alpha_{\mathrm{C}}
$$

where I denotes a chemically inert component that is present in the fresh feed of A. B is available as a pure component. In order for the reactive column to operate successfully reactant $\mathrm{B}$ must be fed above reactant $\mathrm{A}$ and the reactive section of the column must be located between the rectifying section, where the inert component $\mathrm{I}$ is the dominant component, and the stripping section, where product $\mathrm{C}$ is the dominant component. The constants that appear in the description of the case study are presented in Tables 3 and 4.
The steady state model of the reactive column is based on the superstructure representation of Figure 2. NT potential trays (including the partial reboiler and total condenser) are postulated. Index $i$ is used to denote the trays in the column $(i \in I=\{1,2, \cdots, N T-1, N T\})$. We also define the following sets

$$
\begin{gathered}
r e b=\{1\} \\
\text { col }=\{2,3, \cdots, N T-1\} \\
\text { con }=\{N T\}
\end{gathered}
$$

which correspond to the reboiler, trays within the column shell and the condenser $(I=r e b \cup \operatorname{col} \cup \mathrm{con})$. All trays that belong to $\mathrm{col}$ can be reactive trays. The total number of trays is defined implicitly from the location of the tray where the reflux is fed to the column. The two reactants can be fed anywhere between tray 2 and tray NT-1 but the feed tray for component A must lie below that for component B. The following binary variables are defined

$$
\begin{gathered}
\alpha_{i}=1 \text {, if reactant } \mathrm{A} \text { is fed on tray } i, 0 \text {, otherwise } \\
\beta_{i}=1 \text {, if reactant } \mathrm{B} \text { is fed on tray } i, 0 \text {, otherwise } \\
\gamma_{i}=1 \text {, if reflux is fed on tray } i, 0 \text {, otherwise } \\
\delta_{i}=1 \text {, if trayiis a reactive tray, } 0 \text {, otherwise }
\end{gathered}
$$

Apart from the usual incoming and outgoing liquid and vapor streams $\left(L_{i+1}, L_{i}, V_{i-1}, V_{i}\right)$ each tray may have a feed stream of reactant $\mathrm{A}\left(f_{A, i}\right)$ and/or reactant $\mathrm{B}\left(f_{B, i}\right)$ and/or reflux

Table 3. Constants of the Ternary Reactive Distillation Case Study ${ }^{24}$

\begin{tabular}{llcl}
\hline Symbol & & Numerical value & Units \\
\hline$\Delta h_{r x n}$ & Heat of reaction & $-41,840$ & $\mathrm{~kJ} / \mathrm{kmol}$ \\
$\Delta h_{\text {vap }}$ & Heat of vaporization & $29,053.7$ & $\mathrm{~kJ} / \mathrm{kmol}$ \\
$k_{f, 0}$ & Preexponential factor & $2.37 \cdot 10^{19}$ & $\mathrm{kmol} /(\mathrm{h} \cdot \mathrm{kmol})$ \\
$E_{f}$ & Activation energy & 125,520 & $\mathrm{~kJ} / \mathrm{kmol}$ \\
$k_{b, 0}$ & Preexponential factor & $4.6092 \cdot 10^{23}$ & $\mathrm{kmol} /(\mathrm{h} \cdot \mathrm{kmol})$ \\
$E_{b}$ & Activation energy & 167,360 & $\mathrm{~kJ} / \mathrm{kmol}$ \\
$R_{g}$ & Ideal gas constant & 8.314 & $\mathrm{~kJ} /(\mathrm{kmol} \cdot \mathrm{K})$ \\
$A_{\text {sat }}$ & Antoine equation constant & $\mathrm{A}: 12.34$ & $T$ in K, $P^{\text {sat }}$ in bar \\
& ln $P_{j}^{\text {sat }}=A_{\text {sat }, j}-\frac{B_{\text {sat }}}{T}$ & $\mathrm{I}: 12.34$ & \\
& & $\mathrm{~B}: 11.65$ & $\mathrm{~K}$ \\
$B_{\text {sat }}$ & & $\mathrm{C}: 10.96$ & $\mathrm{k}$ \\
$F_{A}$ & Antoine equation constant & 3862 & $\mathrm{kmol} / \mathrm{h}$ \\
$F_{B}$ & A fresh feed molar flowrate $(50 \%$ A $/ 50 \% \mathrm{I})$ & 70.72 & $\mathrm{kmol} / \mathrm{h}$ \\
$P$ & B fresh feed molar flowrate & 45.36 & $\mathrm{bar}$ \\
Product stream & 8 & \\
\hline
\end{tabular}


Table 4. Sizing and Costing Parameters of the Ternary Reactive Distillation Case Study

\begin{tabular}{|c|c|c|c|}
\hline Symbol & & Numerical value & Units \\
\hline$U_{r e b}$ & Overall heat transfer coef. & 0.568 & $\mathrm{~kW} \cdot \mathrm{m}^{-2} \mathrm{~K}^{-1}$ \\
\hline$U_{\text {cond }}$ & Overall heat transfer coef. & 0.852 & $\mathrm{~kW} \cdot \mathrm{m}^{-2} \mathrm{~K}^{-1}$ \\
\hline$\Delta T_{L M, r e b}$ & Log mean temperature difference & 34.8 & $\mathrm{~K}$ \\
\hline$\Delta T_{L M, \text { cond }}$ & Log mean temperature difference & 13.9 & $\mathrm{~K}$ \\
\hline$\pi_{H E}$ & see Eq. 56 & 7296 & $\$$ \\
\hline$n_{H E}$ & see Eq. 56 & 0.65 & - \\
\hline$T_{S}$ & Tray spacing & 0.61 & $\mathrm{~m}$ \\
\hline$\pi_{c o l}$ & see Eq. 60 & 17,640 & $\$$ \\
\hline$n_{C, D}$ & see Eq. 60 & 1.066 & - \\
\hline$n_{C, H}$ & see Eq. 60 & 0.802 & - \\
\hline$\pi_{\text {tray }}$ & see Eq. 60 & 229 & $\$$ \\
\hline$n_{T D}$ & see Eq. 60 & 1.55 & - \\
\hline$c_{\text {steam }}$ & Steam cost & $5.155 \cdot 10^{-6}$ & $\$ / \mathrm{kJ}$ \\
\hline$t_{y}$ & On stream time & 8000 & $\mathrm{~h} / \mathrm{y}$ \\
\hline$N T$ & Number of potential trays & 35 & - \\
\hline
\end{tabular}

$\left(R_{\mathrm{i}}\right)$. As a result the component material balances can be written as follows

$$
\begin{gathered}
L_{i+1} x_{i+1, j}+V_{i-1} y_{i-1, j}+R_{i} x_{N T, j}+f_{A, i} z_{A, j}+f_{B, i} z_{B, j}+n_{j} r_{i} \\
=L_{i} x_{i, j}+V_{i} y_{i, j}, i \in \mathrm{col}, j \in J
\end{gathered}
$$

where $x_{i, j}\left(y_{i, j}\right)$ is the mole fraction of component $j$ $(j \in J=\{A, B, C, D\})$ on tray $i$ in the liquid (vapor) phase, $R_{i}$ is the part of the column reflux that is fed to tray $i, n_{j}$ is the stoichiometric number of component $j$ and $r_{i}$ is the reaction rate on tray $i$. Equations 37-41 that follow are the component and overall material balances

$$
\begin{gathered}
L_{i+1} x_{i+1, j}=L_{i} x_{i, j}+V_{i} y_{i, j}, i \in r e b, j \in J \\
V_{i-1} y_{i-1, j}=\left(\sum_{i^{\prime} \in \text { col }} R_{i}+D\right) x_{i, j}, i \in \text { con }, j \in J \\
L_{i+1}+V_{i-1}+R_{i}+f_{A, i}+f_{B, i}+N r_{i}=L_{i}+V_{i}, i \in \mathrm{col} \\
L_{i+1}=L_{i}+V_{i}, i \in \text { reb }
\end{gathered}
$$

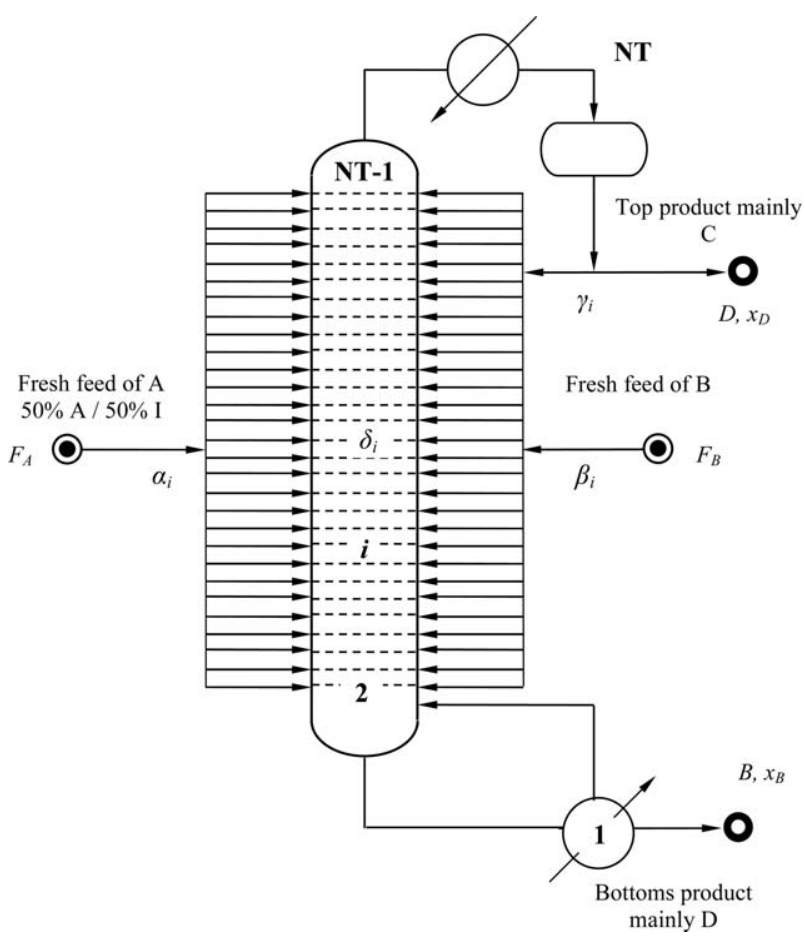

Figure 2. Reactive distillation column superstructure.

$$
V_{i-1}=\sum_{i^{\prime} \in c o l} R_{i}+D, i \in c o n
$$

Ideal behavior is assumed for the vapor-liquid equilibrium, negligible heat of mixing and equal latent heats

$$
\begin{gathered}
\sum_{j \in J} x_{i, j}-\sum_{j \in J} y_{i, j}=0, i \in I \\
y_{i, j} P-x_{i, j} P_{j}^{\text {sat }}\left(T_{i}\right)=0, i \in I, j \in J \\
\left(V_{i}-V_{i-1}\right) \Delta h_{\text {vap }}=r_{i}\left(-\Delta h_{r x n}\right), i \in \mathrm{col}
\end{gathered}
$$

The Integer variables $\delta_{i}$ take the value of 1 if tray $i$ is a reactive tray in which case the mass of catalyst $\left(M_{i, c a t}\right)$ on tray $i$ is a positive constant

$$
0 \leq M_{i, c a t} \leq \delta_{i} M_{c a t}^{U}, i \in \mathrm{col}
$$

$M_{c a t}^{U}$ is the maximum mass of catalyst that can be loaded on trays. Reactants A and B and reflux must each be fed on a single tray and we have the following constraints

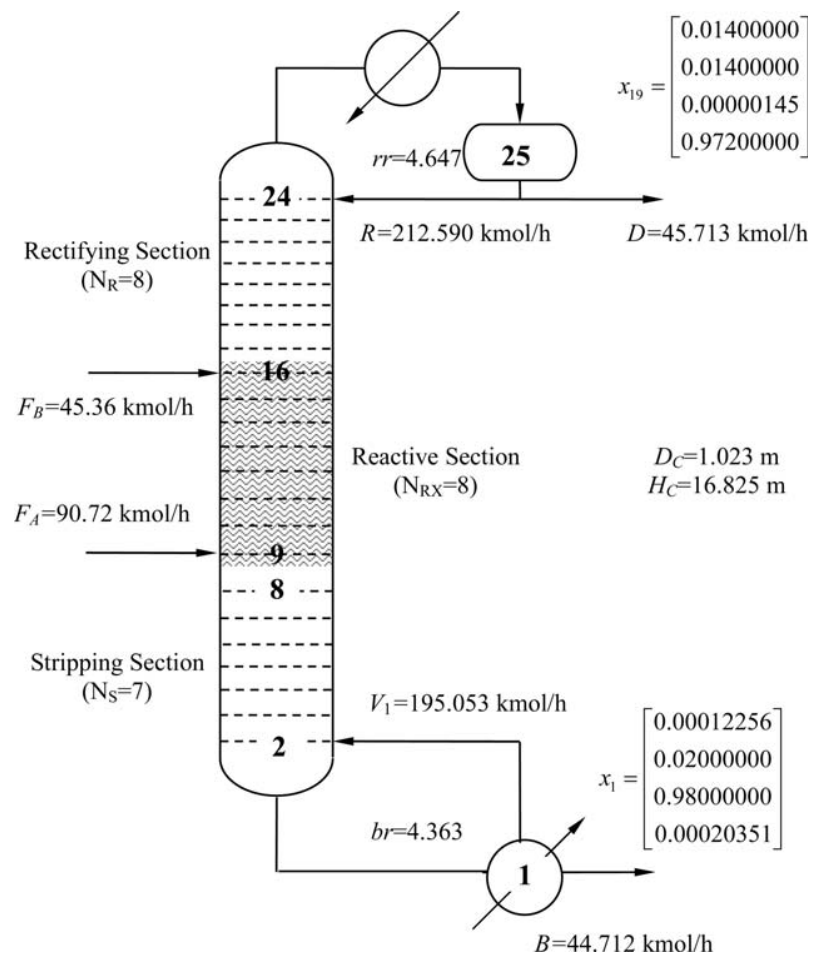

Figure 3. Optimal steady state design of the reactive distillation column. 


$$
\begin{gathered}
f_{A, i}=F_{A} a_{i}, i \in \mathrm{col} \\
\sum_{i \in \mathrm{col}} a_{i}=1 \\
f_{B, i}=F_{B} \beta_{i}, i \in \mathrm{col} \\
\sum_{i \in \mathrm{col} l} \beta_{i}=1 \\
\gamma_{i} R_{L} \leq R_{i} \leq \gamma_{i} R^{U}, \quad i \in \mathrm{col} \\
\sum_{i \in \mathrm{col} l} \gamma_{i}=1
\end{gathered}
$$

where $F_{A}$ is the total molar flowrate of reactant A (see Table 3), $F_{B}$ is the total molar flowrate of reactant B (see Table 3), $R_{L}$ and $R^{U}$ are lower and upper bounds on the reflux flowrate. The constraints that follow ensure that reactant $\mathrm{B}$ will be fed above reactant $\mathrm{A}$ and below reflux (without excluding the possibility for all streams to be fed on the same tray, in which case the distillation column is simplified to a reactive flash) and that the reactive section is located between the trays to which the two reactants are fed

$$
\begin{aligned}
& \sum_{i \in c o l} i \cdot \alpha_{i} \leq \sum_{i \in c o l} i \cdot \beta_{i} \\
& \sum_{i \in c o l} i \cdot \beta_{i} \leq \sum_{i \in c o l} i \cdot \gamma_{i} \\
& \delta_{i} \leq \sum_{i^{\prime}=2}^{i} \alpha_{i^{\prime}}-\sum_{i^{\prime \prime}=2}^{i-1} \beta_{i^{\prime \prime}}
\end{aligned}
$$

The model presented above is augmented with the sizing and costing equations that follow (TAC is the approximate total annual cost)

$$
\begin{gathered}
Q_{r e b}=A_{r e b} U_{r e b} \Delta T_{L M, r e b}=V_{1} \Delta h_{v a p} \\
C_{r e b}=\pi_{H E} A_{r e b}^{n_{H E}} \\
Q_{c o n}=A_{c o n} U_{c o n} \Delta T_{L M, c o n}=V_{N T-1} \Delta h_{v a p} \\
C_{c o n}=\pi_{H E} A_{c o n}^{n_{H E}} \\
1.22 \sqrt{\rho_{V}}\left(\frac{\pi D_{C}^{2}}{4}\right) \geq V_{N T-1} \\
H_{C}=1.2\left(\sum_{i=1}^{N T-1} i \cdot \gamma_{i}-1\right) T_{S} \\
T A C=\left(\frac{C_{c o l}+C_{r e b}+C_{c o n}}{3}\right)+\left(c_{s t e a m} Q_{r e b}+c_{c w} Q_{c o n}\right) t_{y}
\end{gathered}
$$

The numerical values of all constants appearing in the sizing and economics model are given in Table 4. Finally the following product purity constraints are considered

$$
\begin{gathered}
x_{1, C} \geq 0.98 \\
x_{N T, I} \geq 0.971
\end{gathered}
$$

The mathematical problem for the optimal design of the ternary reactive distillation column is an MINLP problem which was solved using the SBB solver available in GAMS. The optimal solution is summarized in Figure 3. The optimal solution has seven trays in the stripping section, eight reactive trays and eight trays in the rectifying section. The diameter of

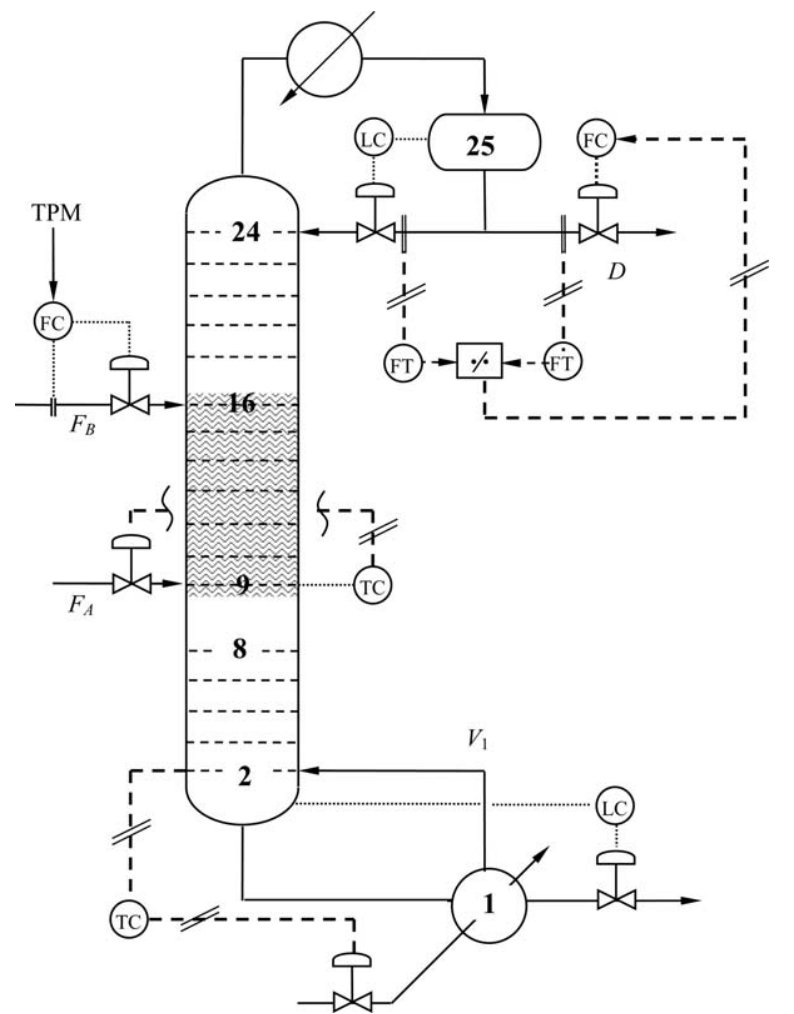

Figure 4. Closed loop system proposed for the ternary reactive distillation column with a chemically inert component in the feed.

the column is $1.023 \mathrm{~m}$ and the height $16.825 \mathrm{~m}$. The reflux ratio is 4.647 and both product quality constraints are active. The conversion of A achieved is $98.5 \%$. The overall cost is TAC $=405,413 \$ / y, 58 \%$ of which is the cost of utilities.

The state vector consists of the mole fractions of components $\mathrm{A}, \mathrm{B}$, and $\mathrm{C}$ on each tray while the potential manipulated variables are the fresh feed molar flowrate of $\mathrm{A}\left(F_{\mathrm{A}}\right)$, the vapor molar flowrate $\left(V_{1}\right)$ and the top product flowrate $(D)$. The feed flowrate of $\mathrm{B}$ is used to control the total production while the bottoms product stream $(B)$ and the reflux flowrate $(\mathrm{R})$ to control the liquid holdups on column base and reflux drum. The potential controlled variables are the temperatures on the trays $\left(T_{2}, T_{3}, \ldots, T_{23}\right)$ and the reflux ratio $(r r)$. We therefore have three potential manipulated variables and 23 potential controlled variables giving rise to 69 potential $1 \times 1$ control structures, 759 potential $2 \times 2$ control structures, and 1771 potential $3 \times 3$ control structures $(2553$ potential control structures in total).

Following the determination of the optimal reactive distillation column design and optimal operating point the linearized model is determined and the matrices necessary to determine the back-off vector are extracted. Then both the linear and nonlinear formulation are applied to derive the most promising regulatory control structures. Disturbance variation was kept small (1\% of nominal values) as the process is expected to demonstrate rather nonlinear dynamics. It was observed that there is a large number of $3 \times 3$ control structures (at least 10 have been developed) which exhibit almost zero economic penalty. These structures involve all potential manipulated variables and the temperature of the first or second tray in the stripping section of the column $\left(T_{2}, T_{3}\right)$, the temperatures of the first or second reactive tray $\left(T_{9}, T_{10}\right)$ and the last two trays 


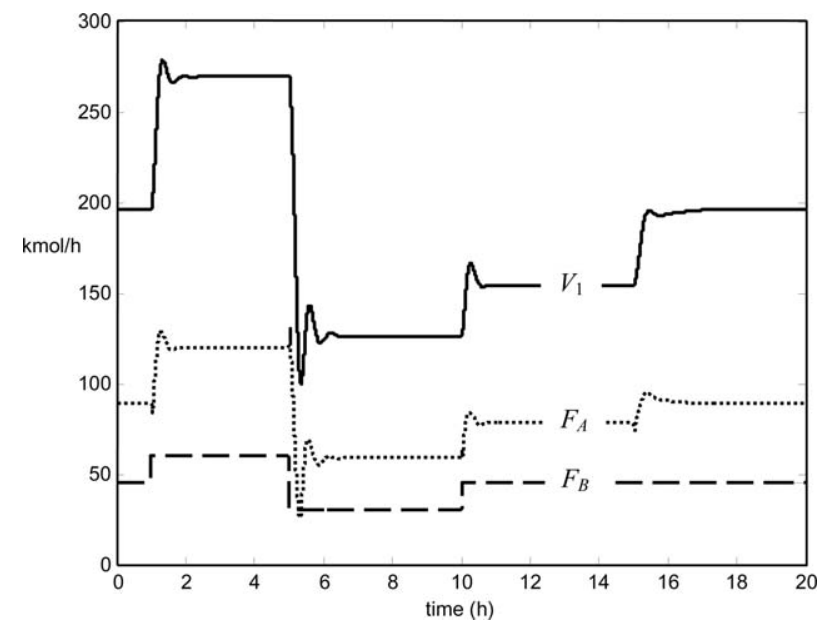

Figure 5. Variation of the manipulated variables-reactive distillation case study.

in the rectifying section $\left(T_{23}, T_{24}\right)$ or the reflux ratio as controlled variables. There is one structure which is the easiest to implement as it involves constant reflux and control of the temperatures in the first trays of the stripping $\left(\mathrm{T}_{2}\right)$ and reactive $\left(\mathrm{T}_{9}\right)$ sections (see Figure 4). According to the analysis based on heuristics presented in Ref. 24 these structures are expected to suffer from severe interactions and large input variability. To evaluate the structures it was decided to perform closed loop simulations for the most promising of them that involves the reflux ratio.

To develop the dynamic model 1 min measurement lags are implemented for the temperature measurements. Simple first order models are fitted to the response of the controlled variables to the variation of the molar flowrate of A and vapor flowrate and PI controller parameters were obtained using classical tuning rules. For the dynamic simulation the molar flowrate of $\mathrm{B}\left(F_{B}\right)$ is increased by $20 \%$ at $\mathrm{t}=1 \mathrm{~h}$, then decreased by $-40 \%$ at $\mathrm{t}=5 \mathrm{~h}$ and then returned to nominal value at $\mathrm{t}=10 \mathrm{~h}$. At this time a $10 \%$ increase in the composition of the inert in the feed is considered which returned to its nominal value at $\mathrm{t}=15 \mathrm{~h}$. This is clearly a very aggressive disturbance variation and failure of the controlled system in keeping the product composition close to the desired value of $98 \%$ was expected.

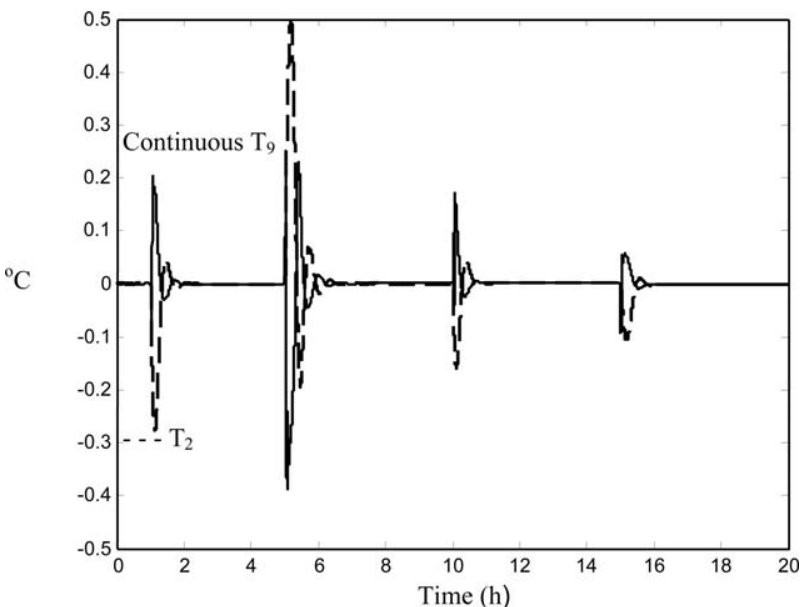

Figure 6. Variation of the controlled variables-reactive distillation case study.

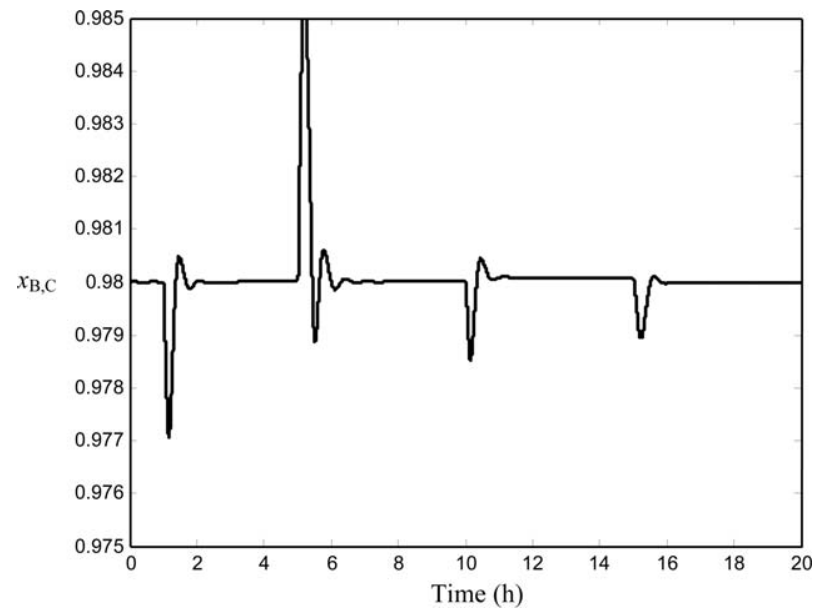

Figure 7. Variation of the product mole fraction in the column bottoms product-reactive distillation case study.

The closed loop system was simulated for $20 \mathrm{~h}$ of operation and the response of the manipulated variables, controlled variables and product composition are shown in Figures 5-7, respectively. As can be observed the performance of the closed loop system is smooth and the deviations of the two controlled temperatures from their set point small. In addition, the deviation of the composition of the product from its desired value is kept very small (less than 0.005) despite the fact that this is not directly controlled. These findings prove that the proposed formulation is successful in identifying promising control structures in a systematic way and has significant advantages over alternative techniques that are base on rules of thumb and heuristics.

\section{Conclusions}

The back-off methodology has been extensively developed and refined in the last 20 and offers a systematic tool for solving the simultaneous design and control problem. Previous work has been based on linear process and control models that exploit the benefits of linear control and optimization theory and ensure quick determination of the optimal solution at the expense of potential loss in the accuracy due to nonlinear process characteristics. In this work a new formulation has been proposed where use is made of a nonlinear process model that allows improved accuracy and also offers the opportunity for the simultaneous consideration of process design and process control. The connection of the new formulation to previous work has been established. Two case studies are studied in detail and demonstrate the advantages of the new improved formulation. In the first case study where an evaporator is considered it was shown that for this model linear and nonlinear formulations give consistent results and both rank successfully the potential control structures. In the second case study, where a ternary reactive distillation column with a chemically inert component in the feed is considered, it was shown that the control structures that were identified as promising resulted in quite satisfactory closed loop performance despite the conclusions of previous researchers. These findings support strongly our argument that the back-off methodology is a promising and efficient methodology for solving the control structure selection problem and the simultaneous design and control problem. 


\section{Literature Cited}

1. Narraway LT, Perkins JD, Barton GW. Interaction between process design and process control: economic analysis of process dynamics. J Process Control. 1991;1(5):243-250.

2. Narraway LT, Perkins JD. Selection of process control structure based on linear dynamic economics. Ind Eng Chem Res. 1993;32: 2681-2692.

3. Kookos IK, Perkins JD. A systematic method for optimum sensor selection in inferential control systems. Ind Eng Chem Res. 1999; 38(11):4299-4308.

4. Heath JA., Kookos IK, Perkins JD. Process control structure selection based on economics. AIChE J. 2000;46(10):1998-2016.

5. Kookos IK., Perkins JD. An algorithmic method for the selection of multivariable process control structures. J Process Control. 2002; 12(1):85-99.

6. Kookos IK, Perkins JD. An algorithm for simultaneous process design and control. Ind Eng Chem Res. 2001;40(19):4079-4088.

7. Psaltis A, Kookos IK, Kravaris C. Plant-wide control structure selection methodology based on economics. Comp Chem Eng. 2013;52: 240-248.

8. Psaltis A, Kookos IK, Kravaris C. Plantwide control structure selection methodology for the benchmark vinyl acetate monomer plant. Comp Chem Eng. 2014;62:108-116.

9. Ellis M, Durand H, Christofides PD. A tutorial review of economic model predictive control methods. J Process Control. 2014;24(8): 1156-1178.

10. Ellis M, Christofides PD. Real-time economic model predictive control of nonlinear process systems. AIChE J. 2015;61(2):555-571.

11. Heo S, Marvin WA, Daoutidis P. Automated synthesis of control configurations for process networks based on structural coupling. Chem Eng Sci. 2014;136:76-87.

12. Heo S, Daoutidis P. Graph-theoretic analysis of multitime scale dynamics in complex material integrated plants. Ind Eng Chem Res. 2015;54(42):10322-10333.
13. Sánchez-Sánchez K, Ricardez-Sandoval LA. Simultaneous process synthesis and control design under uncertainty: a worst-case performance approach. AIChE J. 2013;59(7):2497-2514.

14. Bahakim SS, Ricardez-Sandoval LA. Simultaneous design and MPCbased control for dynamic systems under uncertainty: a stochastic approach. Comput Chem Eng. 2014;63:66-81.

15. Omell BP, Chmielewski DJ. On the tuning of predictive controllers: impact of disturbances, constraints, and feedback structure. AIChE J. 2014;60(10):3473-3489.

16. Yelchuru R, Skogestad S. Quantitative methods for regulatory control layer selection. J Process Control. 2013;23(1):58-69.

17. Maarleveld, A, Rijnsdorp, JE. Constraint control on distillation columns. Automatica 1970;6(1):51-58.

18. Stephanopoulos G. Synthesis of control systems for chemical plants A challenge for creativity. Comput Chem Eng. 1983;7(4):331-365.

19. Pistikopoulos EN. Uncertainty in process design and operations. Comput Chem Eng. 1995;19(S1):553-563.

20. Mohideen MJ, Perkins JD, Pistikopoulos EN. Optimal design of dynamic systems under uncertainty. AIChE J. 1996;42(8):22512272.

21. Bazaraa MS, Sherali HD, Shetty CM. Nonlinear Programming, Theory and Algorithms, 2nd ed. New York: John Wiley \& Sons, 1993.

22. Wolsey LA. Integer Programming. New York: John Wiley \& Sons, 1998.

23. Newell RB, Lee PL. Applied Process Control: A Case Study. New Jersey: Prentice Hall, 1989.

24. Luyben WL. Control of ternary reactive distillation columns with and without chemically inert component. Ind Eng Chem Res. 2007; 46:5576-5590.

25. Brooke A, Kendrick D, Meeraus A, Raman R, Rosenthal RE. Gams A User's Guide. Washington, DC: Gams Development Corporation, 1998.

Manuscript received Feb. 3, 2016, and revision received Apr. 13, 2016. 